\title{
Trimethoprim-sulfamethoxazole prophylaxis against urinary tract infection in the chronic spinal cord injury patient
}

\author{
DS Sandock, BG Gothe and DR Bodner \\ Department of Veterans Affairs Medical Center and Case Western Reserve University School of Medicine \\ Cleveland, Ohio, USA
}

\begin{abstract}
Suppressive therapy with antibiotics has long been thought to decrease the number of complications from the neuropathic bladder in spinal cord injury patients, but it may also induce resistance to antibiotics which subsequently causes difficulties in treating symptomatic urinary tract infections. Forty-three chronic spinal cord injury patients were randomized to continue to receive daily trimethoprim-sulfamethoxazole (TMP-SMX) urinary tract prophylaxis versus discontinuing antibiotic prophylaxis. Patients were all at least 6 months after spinal cord injury. Patients were followed for a minimum of 3 months, with weekly catheter urine cultures. The difference in the colonization rate at onset and after 3 months (percent of cultures with asymptomatic bacteriuria) between the control and prophylaxis group was not statistically significant $(P>0.1)$. There was a significant decrease in the percentage of TMP-SMX resistant asymptomatic bacteriuria in the control group, $78.8 \%$, compared to $94.1 \%$ in the suppressive group $(P<0.05)$. There was no significant difference in the number of symptomatic urinary tract infections following the withdrawal of suppressive therapy between the control group, $0.035 /$ week, and the prophylaxis group, $0.043 /$ week $(P>0.5)$. There was a larger percentage of TMP-SMX resistant symptomatic urinary tract infections in the treated group, $42.5 \%$ versus $37.5 \%$ in the control group, but the difference was not significant $(P>0.5)$. Irrespective of the method of bladder management, suppressive therapy with TMP-SMX did not reduce the incidence of symptomatic bacteriuria and did increase the percentage of cultures resistant to TMP-SMX in asymptomatic patients.
\end{abstract}

Keywords: urinary tract infection; neuropathic bladder; antibiotic suppression; spinal cord injury; trimethoprim-sulfamethoxazole

\section{Introduction}

Up to $90 \%$ of spinal cord injury patients develop bacteriuria within 2-3 weeks of beginning intermittent catheterization, and all patients with indwelling catheters eventually become colonized. ${ }^{1-5}$ Yet controversy exists whether to use prophylactic antibiotics in the spinal cord injury patient. Several studies have shown a significant decrease in asymptomatic bacteriuria with prophylaxis in spinal cord injury patients utilizing intermittent catheterization, ${ }^{1,6-11}$ but few have demonstrated a decrease in symptomatic urinary tract infections. ${ }^{9,10}$ Since it is difficult to eradicate asymptomatic bacteriuria permanently in patients with chronic indwelling catheters, these patients probably do not benefit from prophylaxis. ${ }^{3,3,12}$ We undertook a prospective study to determine the efficacy to TMP-SMX suppressive therapy against asymptomatic bacteriuria and symptomatic urinary tract infections (UTIs) in the chronic spinal cord injury patient to evaluate the effect

Correspondence: Donald R Bodner MD, Department of Urology, 2074 Abington Road, Cleveland, Ohio 44106, USA of suppressive therapy on the incidence of symptomatic episodes of urinary tract infections in treated versus non-treated patients and to determine whether or not discontinuation of suppressive therapy would result in a decrease in resistance of the organisms cultured from the urinary tract.

\section{Methods}

All of the patients in this study were hospitalized in the Spinal Cord Injury Unit at the Cleveland Department of Veterans Affairs Medical Center between February 1992 and May 1993. The unit consists of two identical wards, each with a sixteen-bed open room, two four-bed rooms, two two-bed rooms and two single rooms. TMP-SMX used to be prescribed liberally as a prophylactic/suppressive agent in our unit prior to this study. Patients were assigned to treatment versus control groups as they were admitted to the two separate wards based on prior admission patterns. The treatment group continued to receive TMP $(80 \mathrm{mg})$ SMX $(400 \mathrm{mg})$ daily, while in the control group this treatment was stopped. Patients were excluded for 
hospital stay less than 3 months, antibiotic therapy for febrile illness other than UTI, peri-operative antibiotics, TMP-SMX allergy or intolerance, or lack of informed consent. Of the 80 patients evaluated for the study, 37 were excluded leaving 23 patients in the control group and twenty patients in the treatment group. Patients stayed in the hospital longer than 3 months for a variety of reasons: chronic skin breakdown and breakdown of the outside support structure were the most common reasons for delays in discharge.

All patients were male. The age ranged from 22 to 84 with the average age in the control and treatment groups being 58.3 and 46 years, respectively $(P<0.01)$. The level of injury was comparable, with greater than half of the patients in each group having tetraplegia. The average time from injury was 14.9 years in the control group and 9.2 years in the treatment group $(P>0.1)$. The average time spent on study was 5.9 months in the prophylaxis group and 7 months for the control group. Bladder management was different for the two groups (Table 1) but this was not statistically significant.

Urine cultures were sent weekly and with each symptomatic UTI by the catheter care team using a sterile technique. All specimens were sent from indwelling catheters, voided mid-stream urines, or by intermittent catheterization. Specimens were processed within $1 \mathrm{~h}$ and all organisms were entered by the laboratory. Culture results were recorded for each patient. Sensitivities were run on all cultures with $>=10,000 \mathrm{cfu} \mathrm{cc}^{-1}$. Asymptomatic bacteriuria was defined as a urine culture with $>=10,000 \mathrm{cfu} \mathrm{cc}^{-1}$ with no evidence of tissue invasion. Urinary tract infection was defined as bacteriuria with evidence of tissue invasion. Signs and symptoms of tissue invasion include fever, pyruria, malodorous urine, suprapubic pain, lethargy and increasing autonomic dysreflexia. Patients deemed to have a symptomatic UTI were treated initially empirically and then based on culture results.

The patients' upper tracts were evaluated during the study period by excretory urography or ultrasonography. Upper tracts were similar in both groups. There was one patient in each group with a small, non-infected, asymptomatic renal calculus. There was one patient in the treatment group and two patients in the control group with mild calyectasis. There was no upper tract deterioration nor new stone formation during the study period.

\section{Results}

At the onset of the study there was no significant difference in the prevalence of a nearly $100 \%$ resistance rate of the organisms to TMP-SMX.

\section{Asymptomatic bacteriuria}

There was no difference in the incidence of asymptomatic bacteriuria between the control and the treatment groups. There were 0.241 episodes per week in the control and 0.243 episodes per week in the treatment groups $(P>0.5)$. The colonization rate (percent of cultures with asymptomatic bacteriuria) was lower with prophylaxis $65.4 \%$ versus $75.8 \%$, but the comparison did not reach significance $(P>0.1)$. The percent of cultures with TMP-SMX resistant asymptomatic bacteriuria was significantly lower in the control group; $77.8 \%$ compared to $94.1 \%(P<0.05)$ (Table 2).

\section{Symptomatic bacteriuria}

There were 0.035 symptomatic UTIs per week in the control group and 0.043 episodes per week in the treatment group. There was no significant difference $(P>0.5)$ between the treated and the untreated group with respect to the incidence of symptomatic episodes of UTIs during the duration of the trial. There was also no significant difference in the percentage of TMPSMX resistant UTIs, with $37.5 \%$ in the control group and $42.5 \%$ in the treatment group $(P>0.5)$ (Table 3$)$.

\section{Bacteriology}

The majority of the cultures were Gram negative bacteria, with E. Coli, P. Aeruginosa and Klebsiella species being most common (Table 4). Enterococcus

Table 1 Patient population

\begin{tabular}{|c|c|c|c|}
\hline & Control & $T M P-S M X$ & $P$ value \\
\hline Number of patients & 23 & 20 & \\
\hline Average age (years) & 58.3 & 46.0 & $P<0.01$ \\
\hline \multicolumn{4}{|l|}{ Level of injury } \\
\hline Tetraplegia (C1-C7) & 12 & 13 & \\
\hline Paraplegia (T1-T6) & 5 & 1 & \\
\hline Paraplegia (T7-T12) & 3 & 4 & \\
\hline Lumbar & 3 & 2 & \\
\hline Time from injury (years) & 14.9 & 9.2 & $P>0.1$ \\
\hline Time on study (months) & 7.0 & 5.9 & $P>0.5$ \\
\hline \multicolumn{4}{|l|}{ Bladder management } \\
\hline Intermittent catheterization & 6 & 15 & \\
\hline Reflex voiding & 7 & 2 & \\
\hline Indwelling catheter & 7 & 3 & \\
\hline Suprapubic catheter & 3 & 0 & \\
\hline
\end{tabular}


Table 2 Asymptomatic bacteriuria

\begin{tabular}{lccc}
\hline & Control & TMP-SMX & $P$ value \\
\hline Episodes per week & 0.241 & 0.243 & $P>0.5$ \\
Positive cultures (percent) (colonization rate) & 75.8 & 65.4 & $P>0.1$ \\
Cultures resistant to TMP-SMX (percent) & 77.8 & 94.1 & $P>0.05$ \\
\hline
\end{tabular}

Table 3 Symptomatic urinary tract infections

\begin{tabular}{|c|c|c|c|}
\hline & Control & $T M P-S M X$ & $P$ value \\
\hline $\begin{array}{l}\text { Symptomatic UTIs } \\
\text { week }^{-1}\end{array}$ & 0.035 & 0.043 & $P>0.5$ \\
\hline $\begin{array}{l}\text { Cultures resistant to } \\
\text { TMP-SMX (percent) }\end{array}$ & 37.5 & 42.5 & $P>0.5$ \\
\hline
\end{tabular}

and methicillin resistant Stapylococcus aureus (MRSA) were the most common Gram positive organisms. Patients with MRSA tended to be chronically colonized and were isolated from the rest of the spinal cord injury unit patients. There were no statistically significant differences between the two groups for any of the bacteria types.

\section{Discussion}

We evaluated 43 chronic spinal cord injury patients in order to determine the efficacy of TMP-SMX prophylaxis in this patient population. Our study deals with chronic spinal cord injury patients with all types of bladder management. With TMP-SMX prophylaxis, there is a higher incidence of TMP-SMX resistant bacteriuria that only partially reversed after 3 months of therapy withdrawal. There are several possible reasons for the remaining high resistance rate in the control group: the time interval was too short to see the full effect of therapy withdrawal, cross contamination, too small a sample size, or different morbidity patterns in the two groups. There have been a number of studies evaluating antibiotic prophylaxis in the spinal cord injury patient but most deal with the acutely injured patient undergoing intermittent catheterization. These studies may be categorized by their effect on both asymptomatic bacteriuria and symptomatic bacteriuria. The first group of studies demonstrate a decrease in asymptomatic bacteriuria but no decrease in symptomatic UTIs. Maynard et $a l^{6}$ studied 50 patients with spinal cord injury of less than 6 months undergoing intermittent catheterization. The patients were prospectively randomized to receive prophylaxis (TMPSMX or nitrofurantoin) versus no prophylaxis. The prophylaxis group had significantly less asymptomatic bacteriuria, but no decrease in symptomatic infections. Duffy $e \mathrm{al}^{7}$ evaluated 31 outpatient spinal cord injury patients in a 6 month double blinded crossover study on intermittent catheterization. It is unclear how remote these patients were from injury. The study demonstrated a statistically significant decrease in asymptomatic bacteriuria and no decrease in the rate of symptomatic infections. Anderson ${ }^{8}$ prospectively randomized 64 male patients with recent spinal cord injury to receive nitrofurantoin, intravesical neomycin or both

Table 4 Microbiology of bacteriuria

\begin{tabular}{|c|c|c|c|c|c|}
\hline & \multicolumn{2}{|c|}{ Control } & \multicolumn{2}{|c|}{$T M P-S M X$} & \multirow[t]{2}{*}{$P$ value } \\
\hline & $\begin{array}{l}\text { No. of } \\
\text { subjects }\end{array}$ & $\begin{array}{l}\text { No. of } \\
\text { episodes }\end{array}$ & $\begin{array}{c}\text { No. of } \\
\text { subjects }\end{array}$ & $\begin{array}{l}\text { No. of } \\
\text { episodes }\end{array}$ & \\
\hline \multicolumn{6}{|l|}{ Gram negative } \\
\hline E. Coli & 12 & 45 & 10 & 35 & $P>0.05$ \\
\hline P. Aeruginosa & 15 & 50 & 11 & 22 & $P>0.01$ \\
\hline Klebsiella species & 13 & 46 & 10 & 22 & $P>0.05$ \\
\hline Serratia species & 7 & 15 & 6 & 15 & $P>0.05$ \\
\hline Proteus species & 7 & 16 & 3 & 6 & $P>0.05$ \\
\hline Enterobacter species & 3 & 10 & 0 & 0 & $P>0.05$ \\
\hline Providencia species & 9 & 15 & 3 & 6 & $P>0.05$ \\
\hline Acinetobacter species & 7 & 9 & 4 & 8 & $P>0.05$ \\
\hline Other & 4 & 6 & 3 & 5 & $P>0.05$ \\
\hline Mixed Gram negative & 8 & 12 & 2 & 5 & $P>0.05$ \\
\hline \multicolumn{6}{|l|}{ Gram positive } \\
\hline Enterococci species & 15 & 40 & 8 & 21 & $P>0.05$ \\
\hline \multicolumn{6}{|l|}{ St. Aureus } \\
\hline Methicillin sensitive & 1 & 1 & 1 & 1 & $P>0.05$ \\
\hline Methicillin resistant & 7 & 19 & 2 & 6 & $P>0.05$ \\
\hline Streptococci species & 1 & 5 & 1 & 1 & $P>0.05$ \\
\hline Mixed Gram positive & 6 & 7 & 1 & 2 & $P>0.05$ \\
\hline
\end{tabular}


and compared them to a control group. All three treatment groups showed a significant decrease in asymptomatic bacteriuria. There was only one symptomatic UTI and no conclusions were drawn in this area. Kevorkian et $a l^{1}$ randomized 39 patients to receive methenamine mandelate or placebo. They also demonstrated a statistically significant decrease in asymptomatic bacteriuria and no decrease in symptomatic infections. This study was atypical in that patients were removed from the study if they developed significant bacteriuria, which limited the number of conclusions that could be drawn.

The second group of studies demonstrate a decrease in both asymptomatic bacteriuria and symptomatic UTIs. Gribble et $a l^{9}$ performed a prospective, doubleblind study in which 129 recent spinal cord injury patients were randomized to receive TMP-SMX or placebo. They showed a significant decrease in both asymptomatic bacteriuria and symptomatic UTIs in these patients undergoing intermittent catheterization. However they concluded that 'Adverse complications are common in this population and colonization and breakthrough bacteriuria with TMP-SMX resistant organisms are frequent and may seriously limit the usefulness of this strategy, particularly in an institutional setting'. Krebs et al ${ }^{10}$ prospectively studied 40 recent ( $<6$ months) spinal cord injury patients on intermittent catheterization by randomizing them to oral methenamine mandelate and intravesical hemiacidrin or no prophylactic treatment. There was a decrease with treatment in asymptomatic bacteriuria (34\% versus $69 \%)$ and in symptomatic UTIs (0.02 week $^{-1}$ versus 0.35 week $^{-1}$ ).

The third group of papers include papers that found no decrease in either asymptomatic bacteriuria or symptomatic infections. ${ }^{13,14}$ Our study fits into this category. While we noted a lower incidence of asymptomatic bacteriuria $(65.4 \%$ versus $75.8 \%)$ with prophylaxis, the difference was not significant. There was also no significant difference in the number of symptomatic infections with prophylaxis $(0.043$ week $\left.{ }^{-1}\right)$ or in the control $\left(0.035\right.$ week $\left.^{-1}\right)$. Mohler et al ${ }^{13}$ randomized 46 spinal cord injury patients (duration of injury unspecified) to receive prophylactic TMP-SMX or placebo. They found no difference in the rates of asymptomatic bacteriuria or symptomatic UTIs. Kuhlemeier et al ${ }^{14}$ randomized 161 spinal cord injury patients to receive no treatment, ascorbic acid, TMPSMX, nalidixic acid, methenamine hippurate, or nitrofurantoin. None of the treatments was effective in reducing asymptomatic bacteriuria. Symptomatic UTIs were not assessed in this study.

Group four consists of a paper by Bakke et al ${ }^{11}$ who studied 302 outpatient spinal cord injury patients practicing intermittent catheterization. They found a significant decrease in asymptomatic bacteriuria with methenamine hippurate in their female patients, but the decrease in their male patients was not significant. However, they found a significant increase in symptomatic UTIs with antibiotic therapy greater than 1 month.
Our spinal cord injury unit provides the unique opportunity to study chronic spinal cord injury patients admitted for prolonged periods for both social and medical problems. One problem with our study was the differences between the two populations. The patients were entered into the treatment versus the control groups as they were admitted to one of the two spinal cord injury wards. This decision was made by the Spinal Cord Injury Unit physicians and was primarily based on bed availability and previous admissions; however, some bias was involved leading to one side (our control group) with older patients that were further out from injury. Yet no benefit was found for antibiotic prophylaxis in preventing either asymptomatic bacteriuria or symptomatic urinary tract infections in chronically injured spinal cord injured patients.

\section{Conclusions}

We found an increase in the percentage of TMP-SMX resistant asymptomatic bacteriuria and no decrease in the number of symptomatic UTIs in the TMP-SMX prophylaxis group as compared to the control group. Routine, antibiotic prophylaxis with TMP-SMX is not supported in the chronic spinal cord injury patient.

\section{References}

1 Kevorkian CG, Merritt JL, Ilstrup DM. Methenamine mandelate with acidification: an effective urinary antiseptic in patients with neurogenic bladder. Mayo Clin Proc 1984; 59: 523-529.

2 Silver JR. Management of acute urinary tract infection in acute paraplegic patients with special reference to the paper strip screening test for infection. Paraplegia 1974; 12: 50-63

3 Kunin CM. Care of urinary catheter. In: Kunin CM (ed). Detection, Prevention, and Management of Urinary Tract Infections. 4th edn. Lea and Feibeger: Philadelphia, 1987, pp 245-297.

4 Warren JW, Muncie HL, Bergquist EJ, Hoopes JM. Sequelae and management of urinary infection in the patient requiring chronic catheterization. J Urol 1981; 125: 1-8.

5 Achong MR. Urinary tract infections in the patient with a neurogenic bladder. In: Bloch RF, Basbaum M (eds). Management of Spinal Cord Injuries. Williams and Wilkins: Baltimore, 1986, p 164.

6 Maynard FM, Diokno AC. Urinary infection and complications during clean intermittent catheterization following spinal cord injury. J Urol 1984; 132: 943-946.

7 Duffy L, Smith AD. Nitrofurantoin macro crystals prevent bacteriuria in intermittent catheterization. Urology 1982; 20: 47-49.

8 Anderson RU. Prophylaxis of bacteriuria during intermittent catheterization of the acute neurogenic bladder. J Urol 1980; 123: $364-366$

9 Gribble MJ, Puterman ML. Prophylaxis of urinary tract infection in persons with recent spinal cord injury: A prospective, randomized, double-blind, placebo-controlled study of Trimethoprim-Sulfamethoxazole. AJM 1993; 95: 141-152.

10 Krebs M, Halvorsen RB, Fishman IJ, Santos-Mendoza NS. Prevention of urinary tract infection during intermittent catheterization. J Urol 1984; 131: 82-85.

11 Bakke A, Vollset SE. Risk factors for bacteriuria and clinical urinary tract infections in patients treated with clean intermittent catheterization. J Urol 1992; 149: 527-531.

12 The prevention and management of urinary tract infections among people with spinal cord injuries. Consensus Statement. 
National Institute on disability and Rehabilitation Research, Jan 27-29, 1992.

13 Mohler JL, Cowen DL, Flanigan RC. Suppression and treatment of urinary tract infection in patients with an intermittently catheterized neurogenic bladder. J Urol 1987; 138: 336-340.

14 Kuhlemeier KV, Stover SL, Lloyd LK. Prophylactic antibacterial therapy for preventing urinary tract infections in spinal cord injury patients. J Urol 1985; 134: 514-517. 